\title{
(2) OPEN ACCESS \\ Strengthening emergency care knowledge and skills in Uganda and Tanzania with the WHO-ICRC Basic Emergency Care Course
}

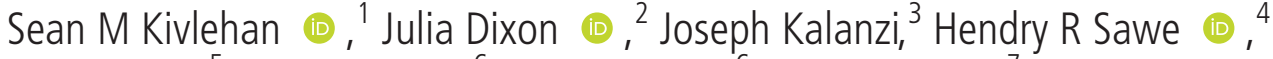 \\ Emily Chien, ${ }^{5}$ Jordan Robert, ${ }^{6}$ Lee Wallis (1) , ${ }^{6}$ Teri A Reynolds ${ }^{7}$
}

\begin{abstract}
Handling editor Richard Body
- Additional supplemental material is published online only. To view please visit the journal online (http://dx.doi. org/10.1136/emermed-2020209718)
\end{abstract}

For numbered affiliations see end of article.

Correspondence to

Dr Sean M Kivlehan, Emergency Medicine, Brigham and

Women's Hospital, Boston MA 02115, USA;

smkivlehan@bwh.harvard.edu

An early version of this manuscript was published as a preprint at https://doi.org/10. 21203/rs.2.19074/v1.

Received 3 April 2020 Revised 21 March 2021 Accepted 25 March 2021 Published Online First 14 April 2021

Check for updates

(c) Author(s) (or their employer(s)) 2022. Re-use permitted under CC BY. Published by BMJ.

To cite: Kivlehan SM,

Dixon J, Kalanzi J,

et al. Emerg Med J

2021:38:636-642

\section{ABSTRACT}

Background There is a pressing need for emergency care (EC) training in low-resource settings. We assessed the feasibility and acceptability of training frontline healthcare providers in emergency care with the World Health Organization (WHO)-International Committee of the Red Cross (ICRC) Basic Emergency Care (BEC) Course using a training-of-trainers (ToT) model with local providers.

Methods Quasiexperimental pretest and post-test study of an educational intervention at four first-level district hospitals in Tanzania and Uganda conducted in March and April of 2017. A 2-day ToT course was held in both Tanzania and Uganda. These were immediately followed by a 5-day BEC Course, taught by the newly trained trainers, at two hospitals in each country. Both prior to and immediately following each training, participants took assessments on EC knowledge and rated their confidence level in using a variety of EC skills to treat patients. Qualitative feedback from participants was collected and summarised.

Results Fifty-nine participants completed the four BEC Courses. All participants were current healthcare workers at the selected hospitals. An additional 10 participants completed a ToT course. EC knowledge scores were significantly higher for participants immediately following the training compared with their scores just prior to the training when assessed across all study sites $(Z=6.23$ $p<0.001)$. Across all study sites, mean EC confidence ratings increased by 0.74 points on a 4-point Likert scale $(95 \% \mathrm{Cl} 0.63$ to $0.84, p<0.001)$. Main qualitative feedback included: positive reception of the sessions, especially hands-on skills; request for additional BEC trainings; request for obstetric topics; and need for more allotted training time.

Conclusions Implementation of the WHO-ICRC BEC Course by locally trained providers was feasible, acceptable and well received at four sites in East Africa. Participation in the training course was associated with a significant increase in EC knowledge and confidence at all four study sites. The BEC is a low-cost intervention that can improve EC knowledge and skill confidence across provider cadres.

\section{INTRODUCTION}

Every day, people seek care for health emergencies. Over $50 \%$ of mortality worldwide can be attributed to emergency medical conditions. ${ }^{1}$ In low-resource settings, the need is particularly great: $90 \%$ of injury related deaths occur in low-income

\section{Key messages}

What is already known on this subject

$\Rightarrow$ There is a significant need for emergency care in low-resource settings, where people suffer from lack of access to timely care and high rates of mortality. Many courses aiming to train providers in these settings are limited by availability of trainers, equipment or cost.

\section{What this study adds}

$\Rightarrow$ This quasiexperimental pretest and post-test study suggests that the WHO-ICRC Basic Emergency Care course can be implemented in low-resource settings by locally trained providers with local equipment at a low cost.

and middle-income countries (LMICs), and patients in LMICs suffer the highest rates of mortality from acute complications of chronic diseases. ${ }^{2}$ Overall, $54 \%$ of annual deaths in LMICs could be potentially addressed by emergency care (EC), suggesting an opportunity to improve these outcomes. ${ }^{4}$ Recognising this need, the World Health Assembly Resolution 72.16 called for increased efforts to strengthen the provision of EC, including training. ${ }^{5}$

Improving patient outcomes for emergency medical conditions requires several conditions to be met including: patient awareness of an emergency medical condition, ability to seek emergency medical care, access to a medical facility capable of providing EC and high-quality care in the emergency unit. ${ }^{67}$ Patients in LMICs face barriers within each of these conditions. Emergency service utilisation rates are extremely low in low-income countries (8 per 1000 population) when compared with high-income countries (264 per 1000 population). ${ }^{8}$ In one review, 192 emergency facilities were identified in 59 LMICs; in the USA alone, there are roughly 5000 emergency facilities. ${ }^{9}$ Utilisation and access to a health facility does not guarantee access to quality EC. Overall mortality rates have been estimated to be extremely high in LMIC emergency units (EUs): $1.8 \%$ as compared with $0.04 \%$ in the USA. ${ }^{9}{ }^{10}$ Paediatric mortality in LMIC EUs has been estimated to be even higher at $4.8 \%$. $^{9}$ Quality of care can be poor due to a lack of resources and variability in provider training. ${ }^{11}$

In order to strengthen EC delivery in resourcelimited settings, the World Health Organization 
(WHO), in collaboration with the International Committee of the Red Cross (ICRC) and the International Federation for Emergency Medicine (IFEM), developed the Basic Emergency Care (BEC) course in 2015, a 5-day intensive training course covering core EC content, including didactics, practical skills and small groups. ${ }^{12}$ Participants are taught a systematic (ABCDE) approach to use for every patient encounter and review signs and symptoms and management of life-threatening conditions during the chief complaint-based modules: shock, trauma, difficulty in breathing, and altered mental status. Content is delivered via didactics and small group exercises. A significant portion of the course is dedicated to practical skills stations that re-emphasise the systematic $\mathrm{ABCDE}$ approach. The course is designed to be taught by local providers who have previously taken the course and attended an additional 2-day train-the-trainer course after completing the BEC. Here, we describe an early implementation of the BEC Course in two East African countries using a trainthe-trainer model.

\section{METHODS}

\section{Study setting and participants}

The BEC Course was implemented in two hospitals in Tanzania and two hospitals in Uganda during March and April of 2017. The implementation was performed with the support of the African Federation for Emergency Medicine (AFEM) in collaboration with the national emergency medicine societies and Ministries of Health of both Tanzania and Uganda. The emergency medicine society leads in each country participated in the development of the BEC Course and identified participating hospital sites based on their high volume of emergency visits, location on major roads and support of hospital leadership. All sites provide EC services, and at all sites these services are delivered in a less formal manner than the standard emergency unit staffed by nonrotating personnel who have received specialised training in trauma and acute care found in high-income countries.

The two participating hospitals in Uganda were Kawolo District Hospital and Mubende Regional Referral Hospital. Kawolo and Mubende are located $40 \mathrm{~km}$ and $170 \mathrm{~km}$, respectively, from the nearest tertiary care facility in Kampala. In Tanzania, the two participating hospitals were Kisarawe District Hospital and Bagamoyo District Hospital. Kisarawe and Bagamoyo are located $42 \mathrm{~km}$ and $65 \mathrm{~km}$, respectively, from the nearest tertiary care facility in Dar-es-Salaam.

\section{Exposure variable}

\section{Participation in BEC Course}

The delivery of the intervention in each country followed the same two-step implementation. First, local providers who participated in a BEC pilot course the previous year participated in a 2-day training-of-trainers (ToT) course, qualifying them to become trainers of the BEC Course. The ToT courses were taught by international faculty involved in the development of the BEC Course and the country leads. These local trainers then delivered the 5-day BEC training to frontline providers who participate in the delivery of acute and emergency medical care. All phases of the intervention were supported in person by a representative of the national emergency medicine society, physicians who participated in the development of the BEC Course and support personnel from AFEM.

BEC Course participants were required to attend all sessions, and attendance was taken. The schedule of the course is shown in figure 1. In all, the course involves 8 core lectures, 6 small group sessions and 25 practical skills taught in six skills stations.

\section{Outcome variables}

A multimethod approach was used to evaluate implementation including an assessment, confidence ratings and feedback surveys. These evaluative tools and their content were developed by the WHO and are a standardised part of the BEC Course package. R V.4.0.1 was used for all statistical analyses; code available on request. ${ }^{13}$

\section{EC knowledge score}

Each participant completed a 25 -question multiple choice assessment immediately prior to and following the course covering core concepts in BEC. The Wilcoxon sign-ranked test was used, due to non-normality, to assess the difference in the median number of questions answered correctly (called EC knowledge score) for each participant on the assessments completed before and after the training. The data are matched by participant.

\section{EC confidence rating}

Each participant also completed a confidence rating questionnaire immediately prior to and following the course. Participants rated their confidence in completing $12 \mathrm{EC}$ actions on a Likert scale of 1 (least confident) to 4 (most confident) (online supplemental appendix 1). The paired samples t-test was used to assess the difference between the mean confidence rating before and after training. Individual responses were not retained at all study sites, precluding the Wilcoxon sign-ranked test from being used to calculate medians or to match based on participant. However, the mean confidence rating for all participants at each of the four study sites for each of the $12 \mathrm{EC}$ actions was available and was matched by skill and site.

\section{Course feedback}

Participants completed structured feedback forms immediately after each BEC module, each block of skills training and the conclusion of the course. Postcourse qualitative data were collected as free text and descriptively analysed by frequency and content of responses. We used the SQUIRE checklist when writing our report. ${ }^{14}$

\section{Cost analysis}

The reported costs of implementing the ToT and BEC courses are the actual expenditures from the project budget. Costs were tracked by site and reported by budget line item, total cost per site and cost per participant.

\section{Patient and public involvement}

The BEC Course was developed in response to an identified public need for EC training applicable to low-resource settings by the WHO and its member states. The study sites, research questions and outcome measures were informed by the priorities and experience of local healthcare providers in Tanzania and Uganda. Local study participants were paid a per diem rate. Local healthcare providers, including the public, will be involved in the dissemination of study results through local and regional advocacy groups.

\section{RESULTS}

\section{Course participants}

Ten participants completed the ToT course: seven in Uganda and three in Tanzania. A total of 59 participants completed the BEC Courses. Forty-six per cent of participants were nurses, 32\% doctors and $22 \%$ other cadres (table 1). Overall course attendance, taken daily, was $97 \%$. 


\begin{tabular}{|c|c|c|c|c|c|}
\hline & DAY 1 & DAY 2 & DAY 3 & DAY 4 & DAY 5 \\
\hline \multirow{2}{*}{0800} & Faculty meeting (0830-0845) & Faculty meeting (0830-0845) & & & Faculty meeting (0830-0845) \\
\hline & \multirow{2}{*}{$\begin{array}{l}\text { Welcome \& Introduction to the BEC } \\
\qquad(0845-0920)\end{array}$} & $\begin{array}{l}\text { Quick review of } \mathrm{ABCDE} \text { and Trauma } \\
\qquad(0845-0900)\end{array}$ & Faculty meeting (0845-0900) & Faculty meeting (0845-0900) & $\begin{array}{c}\text { Review, Today's Plan, Assessments } \\
(0845-0900)\end{array}$ \\
\hline \multirow{2}{*}{0900} & & \multirow[b]{2}{*}{ Approach to DIB (0900-1030) } & $\begin{array}{l}\text { Quick review of DIB and Shock } \\
(0900-0915)\end{array}$ & $\begin{array}{c}\text { Quick review of skills } \\
(0900-0915)\end{array}$ & \multirow{3}{*}{ Altered Mental Status (0900-1045) } \\
\hline & \multirow{2}{*}{$\begin{array}{l}\text { ABCDE Approach } \\
(0920-1040)\end{array}$} & & \multirow{3}{*}{$\begin{array}{l}\text { Skills 1: AIRWAY } \\
\text { (0915-1100) }\end{array}$} & \multirow{3}{*}{$\begin{array}{l}\text { Skills 4: ASSESSMENT } \\
\quad(0915-1100)\end{array}$} & \\
\hline \multirow{2}{*}{1000} & & \multirow{2}{*}{ BREAK $(1030-1100)$} & & & \\
\hline & BREAK (1040-1100) & & & & BREAK (1045-1100) \\
\hline \multirow[b]{2}{*}{1100} & \multirow{2}{*}{$\begin{array}{l}\text { ABCDE small group: Case } \\
\text { Scenarios/MCQ } \\
(1100-1200)\end{array}$} & \multirow[b]{2}{*}{$\begin{array}{l}\text { DIB small group: Case scenarios/MCQ } \\
\qquad(1100-1200)\end{array}$} & BREAK (1100-1115) & BREAK (1100-1115) & \multirow{2}{*}{$\begin{array}{l}\text { AMS small group: Case scenarios } \\
\text { and MCQ }(1100-1200)\end{array}$} \\
\hline & & & \multirow{2}{*}{$\begin{array}{l}\text { Skills 2: BREATHING } \\
\quad(1115-1300)\end{array}$} & \multirow{2}{*}{$\begin{array}{c}\text { Skills 5: IMMOBILIZATION } \\
(1115-1300)\end{array}$} & \\
\hline 1200 & LUNCH (1200-1300) & Handover/Transfer (1200-1230) & & & \\
\hline \multirow[b]{2}{*}{1300} & Icebreaker (1300-1310) & LUNCH (1230-1310) & \multirow[b]{2}{*}{ LUNCH $(1300-1400)$} & \multirow[b]{2}{*}{ LUNCH (1300-1400) } & \multirow[b]{2}{*}{ Lunch (1300-1345) } \\
\hline & \multirow{2}{*}{$\begin{array}{l}\text { TRAUMA PRIMARY SURVEY } \\
\text { Lecture/Demo and SAMPLE (1310- } \\
1430 \text { ) }\end{array}$} & \multirow{2}{*}{$\begin{array}{l}\text { Approach to SHOCK: part } 1 \\
(1310-1405)\end{array}$} & & & \\
\hline \multirow{2}{*}{1400} & & & \multirow{5}{*}{ Skills 3: CIRCULATION (1400-1545) } & \multirow{5}{*}{$\begin{array}{l}\text { Skills 6: WOUND } \\
\text { MANAGEMENT (1400-1545) }\end{array}$} & \multirow{2}{*}{$\begin{array}{l}\text { Medication small groups } \\
\quad(1345-1500)\end{array}$} \\
\hline & BREAK (1430-1450) & \multirow{3}{*}{ Approach to SHOCK: part 2 (1415-1515) } & & & \\
\hline \multirow{4}{*}{1500} & \multirow{4}{*}{$\begin{array}{l}\text { TRAUMA SECONDARY SURVEY plus } \\
\text { demo }(1450-1610)\end{array}$} & & & & \\
\hline & & & & & Course wrap up \\
\hline & & \multirow[b]{3}{*}{$\begin{array}{l}\text { Shock small group: Case scenarios/MCQ } \\
\qquad(1540-1640)\end{array}$} & & & \\
\hline & & & BREAK (1545-1600) & BREAK (1545-1600) & \\
\hline \multirow[t]{2}{*}{1600} & \multirow{2}{*}{$\begin{array}{l}\text { Trauma small group: Case } \\
\text { scenarios/MCQ (1610-1710) }\end{array}$} & & $\begin{array}{l}\text { Skills feedback. Wrap up. } \\
\text { Workbook completion. } \\
(1600-1630)\end{array}$ & $\begin{array}{l}\text { Skills feedback. Wrap up. } \\
\text { Workbook completion. } \\
(1600-1630)\end{array}$ & \\
\hline & & Wrap up (1640-1700) & Close $(1630-1700)$ & Close (1630-1700) & \\
\hline 1700 & $\begin{array}{l}\text { Feedback forms and close (1710- } \\
\qquad 1730)\end{array}$ & & & & \\
\hline
\end{tabular}

Figure 1 Standard schedule for the 5 day BEC course.

\section{Multiple choice assessment}

When assessed across all sites, the median number of questions answered correctly on the 25-question EC knowledge assessment was five points higher on the post-training assessment than on the pretraining assessment (Wilcoxon sign-ranked test, $\mathrm{z}=6.23$, $\mathrm{p}<0.001)$. When assessed by country, the same median increase of five questions was observed for both Uganda and Tanzania as was seen when assessed overall (table 2 and figure 2). When assessed by study site, the median increase in number of correct

\begin{tabular}{lll}
\hline Table 1 & Trainee roles & \\
\hline Role & $\begin{array}{l}\text { Kawolo District Hospital } \\
(\mathbf{n}(\%))\end{array}$ & $\begin{array}{l}\text { Mubende Regional Referral } \\
\text { Hospital (n (\%)) }\end{array}$ \\
\hline Uganda participant characteristics & & $2(20)$ \\
\hline Enrolled nurse & $3(30)$ & $5(50)$ \\
\hline Nursing officer & $4(40)$ & $3(30)$ \\
\hline Medical officer & $3(30)$ & 10 \\
\hline Total & $10(100)$ & Bagamoyo District Hospital \\
\hline Role & Kisaware District & \\
\hline Tanzania participant characteristics & Hospital & 0 \\
\hline Medical attendant & $7(35)$ & $6(32)$ \\
\hline Nurse (officer, enrolled) & $7(35)$ & $6(32)$ \\
\hline Clinical officer & $2(10)$ & $2(11)$ \\
\hline General doctor & $3(15)$ & 0 \\
\hline Nurse midwife & $1(5)$ & $5(26)$ \\
\hline Other (radiographer, dental surgeon, lab & 0 & $19(100)$ \\
\hline tech, pharmacist and nurse anaesthetist) & $20(100)$ & \\
\hline Total & & \\
\hline
\end{tabular}

answers ranged from a three-question improvement at Kawolo District Hospital and at Mubende Regional Hospital to an eightquestion improvement at Bagamoyo District Hospital. Two participants did not complete both the pretest and post-test and were excluded from analysis.

\section{Confidence rating}

Confidence in EC skills also improved significantly at all sites with a mean improvement of 0.74 points (95\% CI 0.63 to 0.84 ) and ranging from a 0.38 to 1.05 absolute increase on a 4-point Likert scale (paired t-test, $\mathrm{t}=14.19, \mathrm{df}=47, \mathrm{p}<0.001$ ). The largest improvements were seen at Kawolo and Bagamoyo District Hospitals (table 3 and figure 3). The same significant increase in mean confidence rating was observed when assessed by site and by country. The data met the requirements necessary for use of the t-test; the sample size was sufficiently large $(n=48$ for overall test) and the assumption of normality was satisfied for the difference between pretraining and post-training (ShapiroWilk test of normality $\mathrm{p}=0.24$, kurtosis $=0.20$, skew $=-0.39$ ). For the two sites where individual responses were retained, a Wilcoxon sign-ranked test demonstrated a similarly significant improvement in median confidence ratings matched by participant (online supplemental appendix 2).

\section{Qualitative themes/responses} Course feedback

Eighty-six per cent (51/59) participated in the postcourse survey. Ninety-five per cent (19/20) of participants from Uganda 
Table 2 Change in median number of questions answered correctly on the EC knowledge assessment using the Wilcoxon sign-ranked test matched on individual scores

\begin{tabular}{|c|c|c|c|c|c|c|c|c|c|}
\hline \multicolumn{2}{|c|}{ Study site } & \multirow[b]{2}{*}{$\mathrm{N}$} & \multicolumn{3}{|c|}{ \# of Q's correct, of 25 (median) } & \multicolumn{4}{|c|}{ Wilcoxon sign-ranked test results } \\
\hline Country & Hospital & & Pretraining & Post-training & Diff & V & $95 \% \mathrm{Cl}$ & $P$ value & (Pseudo) median \\
\hline & Kawolo & 10 & 17.5 & 20.5 & 3 & 36 & 2.5 to 4.5 & 0.011 & 3.0 \\
\hline & Mubende & 10 & 17 & 20 & 3 & 45 & 2.0 to 5.5 & 0.008 & 4.0 \\
\hline \multirow[t]{3}{*}{ Uganda } & & 20 & 14 & 19 & 5 & 153 & 2.5 to 4.5 & $<0.001$ & 3.5 \\
\hline & Kisaware & 19 & 11 & 19 & 7 & 168 & 4.0 to 8.0 & $<0.001$ & 6.0 \\
\hline & Bagamoyo & 18 & 11.5 & 19.5 & 8 & 153 & 5.5 to 9.0 & $<0.001$ & 7.5 \\
\hline Tanzania & & 37 & 14 & 19 & 5 & 627 & 5.5 to 8.0 & $<0.001$ & 6.5 \\
\hline All sites & & 57 & 14 & 19 & 5 & 1372 & 4.5 to 6.5 & $<0.001$ & 5.5 \\
\hline
\end{tabular}

returned feedback on the overall course and $82 \%(32 / 39)$ participants from Tanzania provided postcourse feedback. Participants were asked the following questions: (1) what the participants liked about the course, (2) what participants learnt in the course, (3) what participants would change in the course, (4) who participants would recommend the course to and (5) open-ended additional feedback. Overall, the course was wellreceived by the participants at both the Ugandan and Tanzanian sites. Comments representative of the most frequent feedback and from a diversity of sites and cadres are presented in table 4.

When asked what they liked and/or learnt from the course, $51.0 \%(26 / 51)$ of participants mentioned the ABCDE approach. While other topics such as shock, trauma or SAMPLE (Signs and Symptoms, Allergies, Medications, Past Medical History, Last Oral Intake, and Events Surrounding the Injury or Illness) survey were mentioned, the ABCDE approach stood out as the most mentioned topic. Of this group, $34.6 \%(9 / 26)$ specifically stated they liked the ABCDE approach, and $84.6 \%$ (22/26) specifically mentioned $\mathrm{ABCDE}$ as something they learnt from the course. A

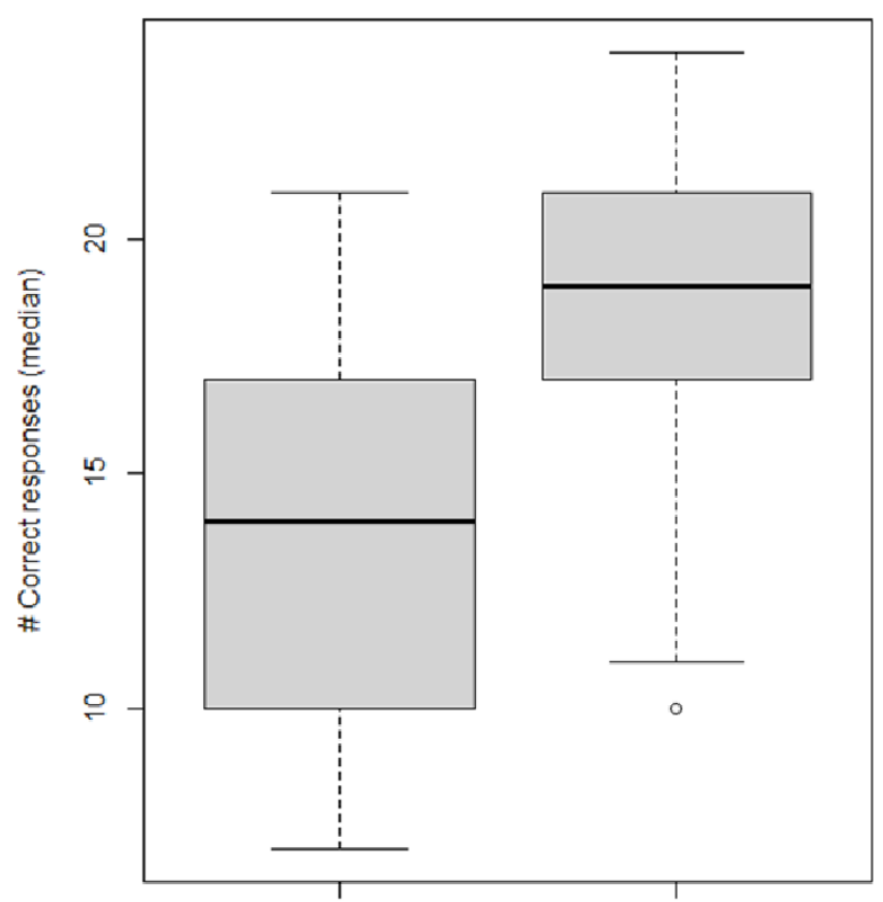

Pre- vs Post-training

Figure 2 Effect of training on EC knowledge scores. EC, emergency care. percentage of 39.2 of participants (20/51) stated that they most enjoyed the skills aspect of the training. Immobilisation, shock and general skills and knowledge in taking care of the emergency patient was the next most cited area of learning from the course followed by topics of trauma, wound care and airway management. A percentage of $25.5(13 / 51)$ of participants stated that the BEC taught them how to better manage emergency patients. Others enjoyed how the course was facilitated as well as the materials provided. A few appreciated that the course was taught in both Swahili and English at the Tanzanian sites.

The most frequent suggestion for improvement was increased time for the course $(21.5 \%, 11 / 51)$, while others stated that they would not change anything about the course $(13.7 \%, 7 / 51)$. Other suggestions for course changes included training more people, sessions on ectopic pregnancy and other obstetric topics and more skills sessions. Most participants felt that this training should be provided to all health providers including nurses and doctors. Many also stated that police officers should also receive this training $(17.6 \% 9 / 51)$. Others stated that all support staff such as security, cleaners and administrators should take this course. Many participants used the open-ended feedback to share that they were planning to apply what they learnt to their clinical work.

\section{Costs}

Ten trainers were trained at an average cost of US\$335 per participant (range \$228-\$442). Fifty-nine healthcare providers were trained at an average cost of $\$ 237$ per participant (range \$171-\$344). The average overall site cost was $\$ 1461$ (range \$1325-\$1596) for the ToT course and \$3394 (range \$1711\$4419) for the BEC Course. Major budget components were for meals (21\% of total budget for ToT and 34\% for BEC), daily per diem reimbursement for the participants $(34 \%$ for ToT and $19 \%$ for BEC) and per diem for local trainers (23\% for ToT and $16 \%$ for BEC) (table 5). Skills equipment was loaned for free from local EC agencies, and space was donated at some sites but required payment at others. Printing was a nominal cost.

\section{DISCUSSION}

This was the first full implementation of the WHO-ICRC-IFEM Basic Emergency Care course, at four hospitals in East Africa, taught by local healthcare providers who completed a ToT course. All sites showed significant improvement in both participant EC knowledge and confidence in performing EC skills after completing the course. Our results were consistent across both parametric and non-parametric statistical tests. The course was well received by participants and supported by hospital administration. Strengths of this study include the recruitment of local healthcare providers to train frontline EC providers at 
Table 3 Testing the change in mean confidence rating for $12 \mathrm{EC}$ skills using a paired t-test matched on the mean confidence rating per question per site

\begin{tabular}{|c|c|c|c|c|c|c|c|c|c|}
\hline \multicolumn{2}{|c|}{ Study site } & \multirow[b]{2}{*}{$\mathrm{N}$} & \multicolumn{2}{|c|}{ Confidence rating, from 1 to 4 (mean) } & \multicolumn{5}{|c|}{$\mathrm{t}$-Test results } \\
\hline Country & Hospital & & Pretraining & Post-training & $\mathbf{t}$ & df & $95 \% \mathrm{Cl}$ & $P$ value & Dmean \\
\hline & Kawolo & 12 & 2.87 & 3.92 & 22.40 & 11 & 0.95 to 1.15 & $<0.001$ & 1.05 \\
\hline & Mubende & 12 & 3.30 & 3.81 & 9.13 & 11 & 0.39 to 0.63 & $<0.001$ & 0.51 \\
\hline \multirow[t]{3}{*}{ Uganda } & & 24 & 2.90 & 3.86 & 11.68 & 23 & 0.64 to 0.92 & $<0.001$ & 0.78 \\
\hline & Kisaware & 12 & 3.25 & 3.63 & 4.92 & 11 & 0.21 to 0.55 & $<0.001$ & 0.38 \\
\hline & Bagamoyo & 12 & 2.88 & 3.88 & 17.75 & 11 & 0.88 to 1.12 & $<0.001$ & 1.00 \\
\hline Tanzania & & 24 & 3.06 & 3.75 & 8.67 & 23 & 0.53 to 0.86 & $<0.001$ & 0.69 \\
\hline All sites & & 48 & 3.07 & 3.81 & 14.19 & 47 & 0.63 to 0.84 & $<0.001$ & 0.74 \\
\hline
\end{tabular}

Table 4 Illustrative comments representative of the most common responses to the feedback questions

\begin{tabular}{|c|c|}
\hline \multicolumn{2}{|l|}{ Feedback question } \\
\hline What did you like about BEC? & $\begin{array}{l}\text { 'It is a comprehensive course and it has equipped me with skills in managing emergency cases using the ABCDE approach'. Clinical officer, Kawolo, Uganda } \\
\text { 'Demonstration of all procedures was very interesting and I have understood well. Also class sessions I have understood and was excellent. Facilitators are very competent with what } \\
\text { they are teaching'. Pharmacist, Bagamoyo, Tanzania }\end{array}$ \\
\hline $\begin{array}{l}\text { What did you learn during the } \\
\text { course? }\end{array}$ & $\begin{array}{l}\text { 'All emergencies should be approached following ABCDE, SAMPLE history and secondary survey. Any life-threatening conditions discovered in ABCDE should be handled immediately'. } \\
\text { Clinical officer, Mubende, Uganda } \\
\text { 'I learned how to manage emergencies using ABCDE approach; I learned how to use SAMPLE approach in history taking; Learned the importance of triage in a health setting; Learned } \\
\text { the common drugs in emergency; I also learned the importance of proper hand over'. Medical officer, Kawolo, Uganda } \\
\text { 'I learned different skills like management of shock, obstructed airway, burn, emergency drugs. Also I learned to have unit/solidarity to the facilitate also to protect myself from } \\
\text { infections. Sharing ideas with others'. Pharmacist, Bagamoyo, Tanzania } \\
\text { 'It changed my attitude towards the care of emergency and handling in terms of ABCDE' Nursing officer, Mubende, Uganda }\end{array}$ \\
\hline Who should take the course? & $\begin{array}{l}\text { 'Yes; all health workers from the gate man, receptionists, nurses, all clinicians+administrator to learn at least the basics'. Nursing officer, Kawolo, Uganda } \\
\text { 'Yes; All health workers; police men/traffic officer; taxi drivers \& boda boda* driver; the general public should be sensitized about this'. Orthopaedic officer, Kawolo, Uganda }\end{array}$ \\
\hline What changes should be made? & $\begin{array}{l}\text { 'The time has to at least go for more than these days because participants need more practice of skills before taking up the duties on the patients'. Nursing officer, Mubende, Uganda } \\
\text { 'Increase course duration - BEC should be conducted several times'. Nurse, Kisarawe, Tanzania }\end{array}$ \\
\hline Open-ended feedback & $\begin{array}{l}\text { 'This course has been an eye opener to me because I didn't know the airway is very important and now am going to give a CME to all the people I work with on the primary approach } \\
\text { of ABCDE 1st'. Nursing officer, Kawolo, Uganda } \\
\text { 'Thank you very much for this Basic emergency course. We are going to put what we have learnt into action in our hospital'. Enrolled nurse, Kawolo, Uganda }\end{array}$ \\
\hline
\end{tabular}

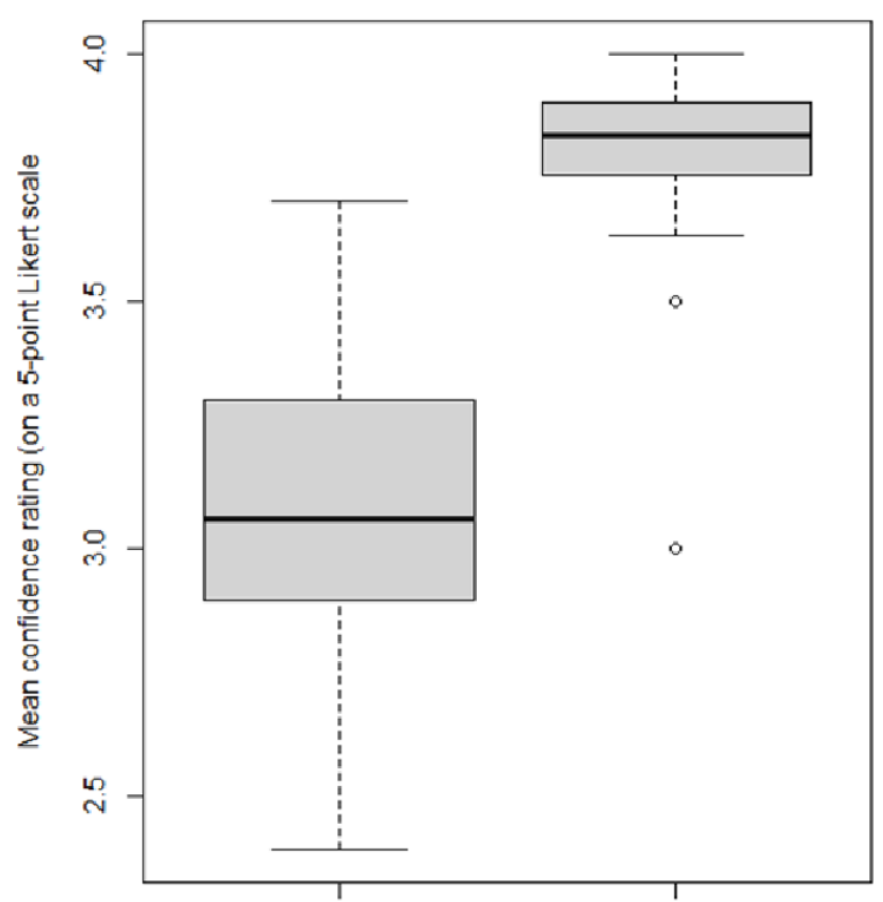

Pre-vs Post-training

Figure 3 Effect of training on confidence in EC skills. EC, emergency care. the implementation sites. Attendance was near perfect, and all but two post-tests were completed. Course skills were taught with locally used equipment, often on loan from the facility hosting the training. Ideally, training occurs at the host facility in donated space. Main feedback themes were: an increase in knowledge and skills, positive reception and recall of the $\mathrm{ABCDE}$ approach, recommendation to teach the BEC Course to all healthcare workers, an ability to manage sick patients, a willingness to incorporate lessons learnt into actual management and the need for more time to complete the training. Feedback collected was reported to the WHO to inform future course revisions.

The BEC Course is designed to strengthen EC systems by improving the quality of care delivered with existing human and material resources in a low-cost and context-appropriate manner. This study demonstrates that the BEC Course can be implemented in a low-resource setting at a low cost by local trainers. Per diem rates for instructors and participants vary by country and will affect the cost of an implementation, and by extension, sustainability. These rates are set by local governments and emergency medicine societies and may incentivise participation in the course to a higher level than would otherwise be attained. In this experience, the per diem rates were substantially higher in Tanzania than in Uganda. Additionally, costs such as printing, equipment and space will vary by location and affect the cost of implementation. Implementation costs can be lowered with scaling of the ToT programme and subsequent elimination of international faculty expenses. Experienced trainers are eligible to lead future ToTs through a process supported by IFEM. ${ }^{15}$ Additional training courses can then be held regionally by 
Table 5 Cost (all costs are in US\$)

\begin{tabular}{|c|c|c|c|c|c|c|}
\hline & \multicolumn{2}{|l|}{ Toт } & \multicolumn{4}{|l|}{ BEC } \\
\hline & \multirow[b]{2}{*}{ Uganda } & \multirow[b]{2}{*}{ Tanzania } & \multicolumn{2}{|l|}{ Uganda } & \multicolumn{2}{|l|}{ Tanzania } \\
\hline & & & Kawalo & Mubende & Kisarawe & Bagamoyo \\
\hline Meals & 426 & 200 & 1588 & 645 & 874 & 1613 \\
\hline Per diem (participants) & 700 & 300 & 223 & 223 & 1066 & 1013 \\
\hline Per diem (local faculty) & 200 & 475 & 109 & 109 & 968 & 931 \\
\hline Space, equipment, projector, airtime & In-kind & 30 & 447 & In-kind & 269 & 451 \\
\hline Printing & Included in Uganda BEC costs & Included in Tanzania BEC costs & 215 & 215 & 315 & 16 \\
\hline Local transport & 0 & 20 & 70 & 56 & 60 & 40 \\
\hline International faculty in-country expenses & 270 & 300 & 792 & 463 & 450 & 355 \\
\hline Overall site cost (average) & 1596 & 1325 & 3444 & 1711 & 4002 & 4419 \\
\hline Cost per participant (average) & 228 & 442 & 344 & 171 & 200 & 233 \\
\hline
\end{tabular}

these local trainers with minimal to no external support further decreasing the cost of each course.

Our study shared strengths found in the implementation of related courses. Implementation of Emergency Triage Assessment and Treatment (ETAT) in Rwandan district hospitals was similarly successful and shared challenges we encountered: intensity of training in a short time period, large clinical responsibilities of students making it difficult to free up time and language barriers. ${ }^{16} 17$ Similar to our qualitative findings, a study in Tanzania showed that the understanding and perception of EC improved at hospitals without formal emergency units after a short training course on EC. ${ }^{18}$ A survey on use of the WHO Pocket Book of Hospital Care for Children in Indonesia found challenges with printing and distributing materials despite systematic mailings of the book by the WHO and Ministry of Health. ${ }^{19}$ While the local EC societies were able to assist in printing and distributing manuals for this implementation, the cost of printing remains a challenge for any future courses. BEC skills are taught using locally sourced equipment and medications, exposing students to the same items used in clinical practice while reducing the supply challenges faced in some other trainings. $^{2021}$

This study has limitations, including the lack of an evaluation of impact on patient outcomes, lack of long-term follow-up of knowledge and skill retention and limited data analysis options due to data inconsistencies between sites. The analysis for the confidence ratings is a compromise based on running the best analysis possible with the pooled dataset from both countries. The results, however, are still strongly significant for the pooled dataset, and for further substantiation of our results, an additional analysis was performed on the more complete subset of data (online supplemental appendix 2). Impact on the quality of actual patient care was not assessed due to cost; however, future research will assess this. A late evaluation of knowledge was not completed due to cost. International faculty were required for course implementation and support because this was an early implementation and there was limited availability of local or regional trainers. As an increased number of providers are trained it is expected that the need for international faculty will be reduced or eliminated, improving sustainability and generalisability. These BEC Courses were held immediately after the ToT courses. As the number of trainers grows, there may be increased time separation between ToT courses the BEC Courses that newly trained trainers teach, which could adversely impact quality.

Future research should evaluate the impact of the BEC Course on patient outcomes and EC process measures. Additionally, the
BEC Course should be tested for validity in settings outside of East Africa and across different languages as translations occur. Finally, long-term knowledge and skill retention should be evaluated though structured follow-up.

\section{CONCLUSION}

Implementation of WHO-ICRC BEC by local provider-trainers was feasible, acceptable and well received at four sites in East Africa. Knowledge assessment scores and trainee confidence increased significantly at all sites. The BEC is a low-cost intervention that can improve knowledge and skill confidence across provider cadres.

\section{Author affiliations}

'Department of Emergency Medicine, Brigham and Women's Hospital, Boston, Massachusetts, USA

${ }^{2}$ Department of Emergency Medicine, University of Colorado School of Medicine, Aurora, Colorado, USA

${ }^{3}$ Department of Emergency Medicine, Makerere University, Kampala, Uganda ${ }^{4}$ Department of Emergency Medicine, Muhimbili University of Health and Allied Sciences, Dar es Salaam, Tanzania

${ }^{5}$ Department of Emergency Medicine, SUNY Downstate Health Sciences University, Brooklyn, New York, USA

${ }^{6}$ Department of Emergency Medicine, University of Cape Town, Rondebosch, Western Cape, South Africa

${ }^{7}$ Integrated Health Services, World Health Organization, Geneve, Switzerland

\section{Twitter Sean M Kivlehan @Sean_Kivlehan}

Acknowledgements We would like to thank the African Federation for Emergency Medicine, the Emergency Medicine Association of Tanzania and Emergency Medicine Uganda for their logistical support.

Contributors SK, JD, HS, JK, LW and TAR contributed to the design of the study. SK, JD, EC and JR collected and analysed data. SK drafted the manuscript. All authors critically reviewed and edited the article and have approved this final version.

Funding This work was supported by the Esther B. Khan Young Investigator in Emergency Medicine Award and a Research Seed Grant, both administered by the Department of Emergency Medicine at the Brigham and Women's Hospital in Boston, Massachusetts, USA.

Competing interests None declared.

Patient consent for publication Not required.

Ethics approval This project was considered exempt by the Partners Human Research Committee and was approved by the Uganda Ministry of Health and the Tanzania President's Office.

Provenance and peer review Not commissioned; externally peer reviewed.

Data availability statement All data relevant to the study are included in the article or uploaded as supplementary information. All data relevant to the study are included in the article.

Supplemental material This content has been supplied by the author(s). It has not been vetted by BMJ Publishing Group Limited (BMJ) and may not have 
been peer-reviewed. Any opinions or recommendations discussed are solely those of the author(s) and are not endorsed by BMJ. BMJ disclaims all liability and responsibility arising from any reliance placed on the content. Where the content includes any translated material, BMJ does not warrant the accuracy and reliability of the translations (including but not limited to local regulations, clinical guidelines, terminology, drug names and drug dosages), and is not responsible for any error and/or omissions arising from translation and adaptation or otherwise.

Open access This is an open access article distributed in accordance with the Creative Commons Attribution 4.0 Unported (CC BY 4.0) license, which permits others to copy, redistribute, remix, transform and build upon this work for any purpose, provided the original work is properly cited, a link to the licence is given, and indication of whether changes were made. See: https://creativecommons.org/ licenses/by/4.0/

\section{ORCID iDs}

Sean M Kivlehan http://orcid.org/0000-0002-4857-4316

Julia Dixon http://orcid.org/0000-0002-9229-2658

Hendry R Sawe http://orcid.org/0000-0002-0395-5385

Lee Wallis http://orcid.org/0000-0003-2711-3139

\section{REFERENCES}

1 Razzak J, Usmani MF, Bhutta ZA. Global, regional and national burden of emergency medical diseases using specific emergency disease indicators: analysis of the 2015 global burden of disease study. BMJ Glob Health 2019:4:e00733.

2 Gosselin RA, Spiegel DA, Coughlin R, et al. Injuries: the neglected burden in developing countries. Bull World Health Organ 2009;87:246-246a.

3 Islam SMS, Purnat TD, Phuong NTA, et al. Non-Communicable diseases (NCDS) in developing countries: a symposium report. Global Health 2014;10:81.

4 Thind A, Hsia R, Mabweijano J. Chapter 14: Prehospital and Emergency Care. In: Debas HT, Donkor P, Gawande A, et al, eds. Essential surgery: disease control priorities. 3rd edn, vol 1. Washington (DC): The International Bank for Reconstruction and Development / The World Bank, 2015

5 World Health Organization. Resolution WHA 72.16: emergency care systems for universal health coverage: ensuring timely care for the acutely ill and injured. Geneva, world health assembly 722019

6 Kobusingye OC, Hyder AA, Bishai D, et al. Emergency medical systems in low- and middle-income countries: recommendations for action. Bull World Health Organ 2005;83:626-31.
7 Calvello EJB, Broccoli M, Risko N, et al. Emergency care and health systems: consensus-based recommendations and future research priorities. Acad Emerg Med 2013;20:1278-88.

8 Chang CY, Abujaber S, Reynolds TA, et al. Burden of emergency conditions and emergency care usage: new estimates from 40 countries. Emerg Med $\mathrm{J}$ 2016:33:794-800.

9 Obermeyer Z, Abujaber S, Makar M, et al. Emergency care in 59 low- and middleincome countries: a systematic review. Bull World Health Organ 2015:93:577-86.

10 Tang N, Stein J, Hsia RY, et al. Trends and characteristics of US emergency department visits, 1997-2007. JAMA 2010;304:664-70.

11 Reynolds TA, Sawe H, Rubiano AM. Chapter 13: Strengthening Health Systems to Provide Emergency Care. In: Jamison DT, Gelband H, Horton S, et al, eds. Disease control priorities: improving health and reducing poverty. 3rd edn. Washington (DC): The International Bank for Reconstruction and Development / The World Bank, 2017.

12 Basic emergency care: approach to the acutely ill and injured. Geneva: World Health organization and the International Committee of the red cross 2018. license: CC BYNC-SA 3.0 IGO.

13 R Core Team. R: a language and environment for statistical computing. Vienna, Austria: R Foundation for Statistical Computing, 2020. https://www.R-project.org/

14 Ogrinc G, Davies L, Goodman D, et al. Squire 2.0 (standards for quality improvement reporting excellence): revised publication guidelines from a detailed consensus process.

15 International Federation of emergency medicine. Available: https://www.ifem.cc/basic emergency-care-training-course/ [Accessed 30 Jun 2020].

16 Hategekimana C, Shoveller J, Tuyisenge L, et al. Correlates of performance of healthcare workers in emergency, triage, assessment and treatment plus admission care (ETAT+) course in Rwanda: context matters. PLoS One 2016;11:e0152882.

17 Hategeka C, Mwai L, Tuyisenge L. Implementing the emergency triage, assessment and treatment plus admission care (ETAT+) clinical practice guidelines to improve quality of hospital care in Rwandan district hospitals: healthcare workers' perspectives on relevance and challenges. BMC Health Serv Res 2017;17:256.

18 Mabula PS, Sawe HR, Mwafongo V, et al. Impact of short basic emergency medicine training in introducing emergency medicine as a specialty in sub-Saharan Africa: experience from Tanzania. Int J Emerg Med 2019;12:3.

19 Li MY, Puspita R, Duke T, et al. Implementation in Indonesia of the who pocket book of hospital care for children. Paediatr Int Child Health 2014;34:84-91.

20 Li MY, Kelly J, Subhi R, et al. Global use of the WHO pocket book of hospital care for children. Paediatr Int Child Health 2013;33:4-17.

21 Kurdin A, Caines A, Boone D, et al. Team: a low-cost alternative to ATLS for providing trauma care teaching in Haiti. J Surg Educ 2018;75:377-82. 